\title{
Colletrotrichum spp: sensibilidade à fungicidas e reação à cultivares de soja
}

\author{
Sylvia Raquel Gomes MORAES ${ }^{1}$, Jaqueline Bezerra da SILVA ${ }^{1}$, \\ Solange Maria BONALDO'1, Wesley Dantas de SOUZA ${ }^{1}$ \\ ${ }^{1}$ Instituto de Ciências Agrárias e Ambientais, Universidade Federal de Mato Grosso, Sinop, MT, Brasil. \\ *E-mail: sylmoraes@yahoo.com.br \\ (Orcid: 0000-0002-4866-8451; 0000-0002-8886-9231; 0000-0002-2240-2700; 0000-0003-3426-3194)
}

\begin{abstract}
Recebido em 18/05/2020; Aceito em 24/06/2021; Publicado em 04/08/2021.
RESUMO: Antracnose é uma das doenças economicamente mais importantes da soja e de difícil controle no Mato Grosso, causando perdas significativas de produtividade. Objetivo foi verificar a sensibilidade de fungicidas e reação de cultivares de soja a 30 isolados de Colletotrichum. A ação de sete fungicidas (azoxistrobina + ciproconazol, piraclostrobina + epoxiconazol, trifloxistrobina + protioconazol, piraclostrobina, carbendazim, fluxpiroxada + piraclostrobina e azoxistrobina) foi avaliada medindo o crescimento micelial in vitro. Todos os fungicidas afetaram o crescimento micelial, mas piraclostrobina + epoxiconazol e piraclostrobina foram os mais eficientes. Além disso, 6 cultivares foram inoculadas com 27 isolados para análise de tombamento pré e pós-emergência, incidência e severidade da doença. Os dados de incidência e severidade foram submetidos à fórmula da Área Abaixo da Curva de Progresso da Doença. Interação significativa foi observada entre isolados e cultivares em todas as variáveis. Os isolados IT-4, IT-6, LU-3, MT-1, NU-5, PN-1, QU-2, SO-6, SO-11 e VR1 apresentaram maior tombamento e AACPD. Exceto QU-2 todos os isolados apresentam conídios falcados. As cultivares 8866, 1179 e 9144 apresentaram menor incidência e severidade da doença.
\end{abstract}

Palavras-chave: Glycine max; tombamento; incidência; severidade; antracnose.

\section{Colletotrichum spp.: Sensibility to fungicides and reaction of commercial germoplasm of soybean}

\begin{abstract}
Anthracnose is one of the most economically important disease of soybean and difficult to control at Mato Grosso State, causing significant yield losses. Objective was to verify the fungicides sensitivity and soybean cultivars reaction to 30 isolates of Colletotrichum. The action of seven fungicides (azoxystrobin+cyproconazole, pyraclostrobin+epoxiconazole, trifloxystrobin+ protioconazole, pyraclostrobin, carbendazim, fluxpyroxade+pyraclostrobin and azoxystrobin) was evaluated measuring in vitro mycelial growth. All fungicides affected the mycelial growth development, but pyraclostrobin + epoxiconazole and pyraclostrobin were the most efficient. Besides, 6 soybean cultivars were inoculated with 27 isolates to analyze pre and post-emergence damping-off, disease incidence and severity. Incidence and severity data were submitted to the formula Area Under the Disease Progress Curve. Significant interaction was observed between isolates and cultivars in all variables. Isolates IT-4, IT-6, LU-3, MT-1, NU-5, PN-1, QU-2, SO-6, SO-11 and VR-1 showed higher damping-off and AUDPC. Excepting the QU-2, all isolates have falcate conidia. Cultivars 8866, 1179 and 9144 presented the lowest disease severity and incidence.
\end{abstract}

Keywords: Glycine max; damping-off; incidence; severity; anthracnose.

\section{INTRODUÇÃO}

A cultura da soja (Glycine Max (L.) Merr.) é uma das principais commodities agrícolas. Na safra 2019-2020 a produção estimada do Brasil é de 124,2 milhões de toneladas, o que significa acréscimo de $8 \%$, ultrapassando os Estados Unidos como maior produtor de soja no mundo (USDA, 2020). A Região Centro-Oeste contribui com 45,2\% dessa produção total com $16.574 \mathrm{mi}$ hectares plantados, sendo $10.004 \mathrm{mi}$ hectares no estado de Mato Grosso (CONAB, 2020). Mas apesar da elevada produção, algumas doenças surgiram com proeminente incidência e vem causando expressivas perdas se não houver um sistema de manejo adequado, como é o caso da antracnose (DIAS et al., 2016).

Colletotrichum truncatum (Schw.) Andrus \& Moore (syn. C. dematium f. truncatum (Schw.) Arx) é a principal espécie associada a antracnose na cultura da soja (HARTMAN et al.,
2015), entretanto outras espécies foram relatadas em estudos realizados no Brasil (BARBIERI et al., 2017; DIAS et al., 2018), Estados Unidos (YANG et al., 2012; YANG et al., 2014), Malásia (MAHMODIA et al., 2013), Taiwan (CHEN et al., 2006) e Argentina (RAMOS et al., 2013).

O Colletotrichum causa manchas de coloração marrom na planta, lesões necróticas na haste e vagem podendo impedir o enchimento dos grãos de soja. As sementes são o principal veículo de transmissão desse patógeno, podendo causar tombamento de pré e pós emergência ou permanecer latente manifestando o sintoma em diferentes estádios de desenvolvimento da planta (SINCLAIR, 1991; HARTMAN et al., 2015). Dessa forma, os métodos a serem adotados para obter resultados positivos no final de cada safra são a utilização de sementes livres do patógeno e/ou tratadas com 
fungicidas; uso de cultivares adequadas; eliminação de restos culturais; aplicação de fungicidas durante o ciclo da cultura; rotação de cultura e adubação equilibrada com ênfase no potássio (EMBRAPA, 2003; HARTMAN et al., 2015).

$\mathrm{O}$ uso de produtos químicos para o controle da antracnose é uma alternativa importante para garantir alta produtividade e qualidade, visto que não há cultivares de soja resistentes a antracnose no mercado. Pesquisadores da Fundação MT apontam que "os produtos disponíveis no mercado não têm alta eficiência no combate a antracnose. Depois de instalada, a doença dificilmente terá controle" (SOJA BRASIL, 2014). O mesmo ocorre no estado do Tocantins onde o controle químico também é limitante no controle da antracnose da soja (DIAS et al., 2016).

Com o indicativo de que o controle químico e/ou genético não está sendo efetivo na redução da incidência de antracnose, o objetivo do trabalho foi selecionar alguns isolados de Colletotrichum presentes nas principais regiões produtoras do estado de Mato Grosso e verificar a sensibilidade dos mesmos a diferentes ingredientes ativos, in vitro; e observar a agressividade dos isolados a seis cultivares de soja.

\section{MATERIAL E MÉTODOS}

Os experimentos foram conduzidos no Laboratório de Fitopatologia e Microbiologia e na casa de vegetação, na Universidade Federal de Mato Grosso, campus Sinop, MT.

\subsection{Isolados}

Os isolados de Colletotrichum foram coletados de plantas de soja com sintomas de antracnose, em diferentes municípios do estado de Mato Grosso (Tabela 1).

Os fragmentos de vagem, caule e pecíolo foram desinfestados, depositados em placas de Petri com ágar-água e incubadas a $25{ }^{\circ} \mathrm{C}$ para obtenção dos isolados fúngicos. Após o crescimento micelial, o mesmo foi repicado para meio de cultura batata-dextrose-ágar (BDA) para posterior obtenção de cultura monospórica, utilizando a técnica de diluição sucessiva.

Para verificar a morfologia do conídio, os isolados foram repicados em meio BDA e incubados a $25{ }^{\circ} \mathrm{C}$, no escuro. Após 7 dias, lâminas foram preparadas com as suspensões fúngicas. Os conídios foram classificados em três grupos, de acordo com o formato: 1) clavado; 2) cilíndrico, reto; ou 3) fusiforme, diretamente atenuado em cada extremidade (SUTTON, 1980).

\subsection{Sensibilidade de isolados aos fungicidas}

Os ensaios foram realizados por meio de testes in vitro. Os fungicidas foram incorporados ao meio de cultura adotandose a técnica descrita por Menten et al. (1976). No preparo da suspensão fúngica os fungicidas foram dissolvidos em acetona $1 \%$ antes de serem incorporadas ao meio BDA (100 $\mathrm{mL}$ ). Foram testados os ingredientes ativos descritos na Tabela 2.

As doses indicadas foram calculadas baseadas nas recomendações técnicas, ou seja, utilizando-se o volume total de calda ( $250 \mathrm{~L} /$ hectare) e dose recomendada do produto. As mesmas foram convertidas em microlitros $(\mu \mathrm{l})$ para adequarse a metodologia utilizada.
Tabela 1. Denominação, formato de conídio, procedência e ano de coleta de isolados de Colletotrichum spp. coletados de plantas de soja sintomáticas no estado do Mato Grosso.

Table 1. Identification isolate code, shape, municipalities and year of Colletotrichum isolates collection from soybean anthracnose symptoms in Mato Grosso state.

\begin{tabular}{cccc}
\hline $\begin{array}{c}\text { Isolado } \\
\text { (Sigla) }\end{array}$ & $\begin{array}{c}\text { Morfologia } \\
\text { conídios }\end{array}$ & Município da coleta & Ano de coleta \\
\hline BG-1* & - & Barra do Garça & 2012 \\
CH-3 & Fusiforme & Chapada dos Guimarães & 2014 \\
CJ-1 & Clavado & Campos de Júlio & 2013 \\
CL-5 & Cilíndrico & Cláudia & 2012 \\
CL-6 & Fusiforme & Cláudia & 2013 \\
CL-7 & Cilíndrico & Cláudia & 2013 \\
CN-1* & Clavado & Campo Novo do Parecis & 2012 \\
IN-1 & Clavado & Ipiranga do Norte & 2012 \\
IT-4 & Clavado & Itaúba & 2013 \\
IT-6 & Clavado & Itaúba & 2014 \\
LU-3 & Clavado & Lucas do Rio Verde & 2014 \\
MT-1 & Clavado & Matupá & 2014 \\
NA-1 & Cilíndrico & Americana do Norte & 2012 \\
NB-1 & Cilíndrico & Nobres & 2014 \\
NU-2 & Cilíndrico & Nova Mutum & 2012 \\
NU-5 & Clavado & Nova Mutum & 2014 \\
NX-1 & Clavado & Nova Xavantina & 2014 \\
PE-4 & Cilíndrico & Peixoto de Azevedo & 2014 \\
PN-1 & Clavado & Porto Alegre do Norte & 2014 \\
QU-2 & Fusiforme & Querência & 2013 \\
RO-1 & Cilíndrico & Rondonópolis & 2013 \\
SC-1 & Fusiforme & Santa Carmem & 2012 \\
SI-3 & Cilíndrico & Sinop & 2013 \\
SO-5 & Cilíndrico & Sorriso & 2013 \\
SO-6 & Clavado & Sorriso & 2013 \\
SO-9* & Cilindrico & Sorriso & 2014 \\
SO-11 & Clavado & Sorriso & 2014 \\
TB-2 & Clavado & Tabaporã & 2013 \\
VE-5 & Clavado & Vera & 2013 \\
VR-1 & Clavado & Vila Rica & 2014 \\
\hline
\end{tabular}

*Isolados não utilizados no ensaio de cultivares

— Não houve esporulação

Tabela 2. Fungicidas utilizados nos ensaios de Colletotricbum. Table 2. Fungicides used in the Colletotrichum assays.

\begin{tabular}{|c|c|c|c|}
\hline Ingrediente ativo & Produto & Grupo químico & Dose (L/ha) \\
\hline Piraclostrobina & Comet $^{(\mathbb{R}}$ & Estrobirulina & 0,30 \\
\hline $\begin{array}{l}\text { Azoxistrobina }+ \\
\text { Benzovindiflupir }\end{array}$ & Elatus $^{\circledR}$ & Estrobirulina & 0,2 \\
\hline $\begin{array}{l}\text { Trifloxistrobina }+ \\
\text { Protioconazol }\end{array}$ & $\operatorname{Fox}^{\circledR}$ & $\begin{array}{l}\text { Estrobirulina }+ \\
\text { Triazolinthione }\end{array}$ & 0,35 \\
\hline Carbendazim & Nortox $^{(}$ & Benzimidazol & 0,45 \\
\hline $\begin{array}{l}\text { Piraclostrobina }+ \\
\text { Epoxiconazol }\end{array}$ & Opera $^{\circledR}$ & $\begin{array}{c}\text { Estrobirulina }+ \\
\text { Triazol }\end{array}$ & 0,55 \\
\hline $\begin{array}{l}\text { Fluxapiroxade + } \\
\text { Piraclostrobina }\end{array}$ & Orkestra $^{\circledR}$ & $\begin{array}{c}\text { Carboxamida }+ \\
\text { Estrobirulina }\end{array}$ & 0,30 \\
\hline $\begin{array}{l}\text { Azoxistrobina + } \\
\text { Ciproconazol }\end{array}$ & $\begin{array}{l}\text { Priori } \\
\text { Xtra }^{\circledR}\end{array}$ & $\begin{array}{c}\text { Estrobirulina }+ \\
\text { Triazol }\end{array}$ & 0,30 \\
\hline
\end{tabular}

\subsubsection{Crescimento micelial}

Os fungicidas foram adicionados ao meio de cultura BDA através de soluções preparadas previamente, seguido de homogeneização. Após 24 horas, disco de micélio $(5 \mathrm{~mm}$ de diâmetro) foi transferido para o centro do meio de cultura BDA com fungicida e sem fungicida (controle). O controle consiste em placas com meio de cultura sem fungicida (testemunha absoluta) e com placas com meio de cultura sem fungicida, porém acrescido de acetona 1\%. Foram demarcados dois diâmetros ortogonais na parte inferior da placa a partir do eixo central. As medições do crescimento micelial foram diárias, a partir do segundo dia após a repicagem. Os fungos permaneceram incubados em câmara de crescimento, a $25 \pm 2{ }^{\circ} \mathrm{C}$, escuro, durante os sete dias de avaliações. 
O índice de velocidade de crescimento micelial (IVMC), expresso em $\mathrm{cm} \cdot \mathrm{dia}^{-1}$, foi utilizado para as análises estatísticas. Os IVMC (Equação 1) foram calculados conforme a fórmula descrita por Oliveira (1991).

$$
\mathrm{IVCM}=\Sigma(\mathrm{D}-\mathrm{Da}) / \mathrm{N}
$$

sendo: $D$ o diâmetro médio atual da colônia; $D a$ diâmetro médio da colônia do dia anterior; e $N$ número de dias após a inoculação.

\subsection{Reação de cultivares de soja a antracnose}

Foram analisados a agressividade de 27 isolados de Colletotrichum spp. (Tabela 1) em seis cultivares comerciais de soja, recomendadas para o estado do Mato Grosso.

\subsubsection{Inoculação das sementes}

A inoculação das sementes foi realizada por meio da técnica de restrição hídrica utilizando meio de cultura BDA acrescido de soluto manitol no potencial hídrico de -0,6 MPa.

Após o crescimento micelial dos isolados em meio BDA acrescido de manitol, sementes previamente desinfestadas com solução de hipoclorito a $1 \%$ foram depositadas sobre o micélio fúngico. Cada placa recebeu 20 sementes de soja das cultivares TMG 132 RR, TMG 1179 RR, TMG 1188 RR, MONSOY 9144 RR, MONSOY 8866 ou IPRO AGROESTE 3820 convencional. As sementes foram levemente pressionadas sobre a massa micelial. Para as testemunhas, as sementes foram depositadas em meio BDA acrescidas de manitol, porém sem a presença do patógeno.

As placas foram colocadas em câmara de crescimento a $25^{\circ} \mathrm{C}$, no escuro, por 12 horas.

\subsubsection{Semeadura}

Decorrido 12 horas, sementes inoculadas foram depositadas em vasos (3L) com substrato comercial Vivatto ${ }^{\circledR}$. Foram colocadas 3 sementes da mesma cultivar por vaso, entretanto, no sétimo dia após a semeadura ocorreu o desbaste de plântulas, deixando 2 plantas/vaso, ou seja, 12 plântulas de soja de cada cultivar por isolado.

\subsubsection{Avaliações}

Foram avaliadas 3 variáveis: porcentagem de plântulas com tombamento pré e pós emergência, incidência e severidade da doença. Para avaliar o tombamento, as plântulas com sintoma de tombamento receberam nota $1 \mathrm{e}$ as plântulas com ausência desse sintoma receberam nota zero. Essa avaliação ocorreu no sétimo dia após a semeadura.

A incidência foi analisada através do número de plantas que apresentaram sintomas de antracnose. E os dados de severidade foram obtidos através da medida das lesões $(\mathrm{mm})$ comparada à escala de notas de severidade de acordo com Costa et al. (2006). Para a incidência e a severidade, foram realizadas 5 avaliações com intervalos de 4 dias a fim de observar o avanço dos sintomas ao longo do tempo. A primeira avaliação ocorreu entre os estádios de desenvolvimento Vc e V1 e a última avaliação no estádio V3.

Os dados foram submetidos à equação da Área Abaixo da Curva de Progresso da Doença (AACPD) (Equação 2), de acordo com Campbell; Madden (1990).

$\mathrm{n}-1$

$\mathrm{AACPD}=\Sigma\left[\left(\mathrm{X}_{\mathrm{i}}+\mathrm{X}_{\mathrm{i}+1}\right) / 2\right]\left(\mathrm{t}_{\mathrm{i}+1}-\mathrm{t}_{\mathrm{i}}\right)$ em que: $X$ é a intensidade da doença, $t$ o tempo e $n$ o número de avaliações no tempo. Os valores obtidos foram analisados estatisticamente.

\subsection{Análise estatística}

O delineamento experimental utilizado foi inteiramente casualizado (DIC). No bioensaio de sensibilidade dos isolados a fungicidas foram nove tratamentos, sendo sete fungicidas e duas testemunhas. Para casa isolado foram utilizados 5 repetições. Para as reações de cultivares foi utilizado fatorial $27 \times 6$, sendo 27 isolados inoculados em 6 cultivares de soja. Foram utilizados 12 repetições, sendo cada planta uma repetição.

Os dados foram submetidos à análise de variância, utilizando a programa de estatística SISVAR. Os valores foram comparados pelo teste Scott-Knott a $5 \%$ de probabilidade (FERREIRA, 2011).

\section{RESULTADOS}

\subsection{Sensibilidade dos isolados a fungicidas}

Todos os ingredientes ativos foram eficientes na redução do crescimento micelial in vitro. No entanto, houve ampla variação na sensibilidade dos isolados de Colletotrichum aos ingredientes ativos (Tabela 3).

Em relação a testemunha absoluta e testemunha com acetona, 30\% dos isolados apresentaram diferença entre elas (MT-1, NB-1, NU-5, PN-1, QU-2, VE-5, VR-1, TB-2 e PE4). Para os dois últimos a testemunha com acetona apresentou valores superiores à testemunha absoluta.

Dentre os ingredientes ativos destaca-se o piraclostrobina + epoxiconazol, que apresentou $100 \%$ de inibição do crescimento micelial nos isolados BG-1, CJ-1, CL-6, CN-1, IT-4, IT-6, MT-1, NU-2, NU-5, NX-1, PN-1, QU-2, SC-1, SI-3, SO-6, SO-9, SO-11, TB-2, VE-5, VR-1, além de baixo crescimento micelial nos demais.

A ação apenas da piraclostrobina também foi eficiente na inibição do crescimento micelial in vitro. $\mathrm{O}$ ingrediente ativo inibiu totalmente o crescimento de $60 \%$ dos isolados (CJ-1, CL-6, CN-1 IT-4, IT-6, LU-3, MT-1, NU-2, NU-5, NX-1, PN-1, QU-2, SI-3, SO-6, SO-11, TB-2, VE-5, VR-1) e parcialmente nos demais.

$O$ terceiro ingrediente ativo mais eficiente foi $o$ azoxistrobina + benzovindiflupir, seguido de trifloxistrobina + protioconazol os quais inibiram completamente o crescimento micelial de 14 e 8 isolados, respectivamente. Por outro lado, a mistura azoxistrobina com o ciproconazol inibiu totalmente o crescimento micelial de apenas três dos 30 isolados avaliados.

Comparando os isolados provenientes do mesmo município pode se observar que os isolados provenientes do município de Cláudia, o CL-7 apresentou crescimento micelial em todos os tratamentos. Entretanto, piraclostrobina, trifloxistrobina + protioconazol $e$ piraclostrobina + epoxiconazol não diferiram estatisticamente, apresentando maior porcentagem de inibição do crescimento micelial 87,8, 84,8, 84,5\%, respectivamente. $\mathrm{O}$ mesmo não foi observado nos isolados CL-5 e CL-6. O crescimento micelial de CL-6 foi completamente inibido por todos os ingredientes ativos. $\mathrm{O}$ isolado CL-5 foi completamente inibido por trifloxistrobina + protioconazol diferindo estatisticamente dos demais tratamentos. Dessa forma, observamos que dentro do mesmo município há variabilidade na sensibilidade dos 
isolados de Colletotrichum aos ingredientes ativos, explicando a ineficiência do controle químico na redução da doença. $\mathrm{O}$ mesmo foi observado nos isolados provenientes do município de Sorriso. No isolado SO-6, 100\% do crescimento micelial foi inibido nos tratamentos com piraclostrobina, azoxistrobina + benzovindiflupir, carbendazin, piraclostrobina + epoxiconazol e azoxistrobina + ciproconazol. No isolado SO-9, a inibição total aconteceu nos tratamentos azoxistrobina + benzovindiflupir, piraclostrobina + epoxiconazol, fluxapiroxade + piraclostrobina e azoxistrobina + ciproconazol. E no isolado SO-5 nenhum ingrediente ativo inibiu $100 \%$ do crescimento micelial.
Por outro lado, no município de Itaúba os isolados apresentaram semelhança quanto a sensibilidade aos diferentes ingredientes ativos. Os isolados IT-4 e IT-6 não cresceram em placas com piraclostrobina, azoxistrobina + benzovindiflupir e piraclostrobina + epoxiconazol. Para isolados do município de Nova Mutum, piraclostrobina e piraclostrobina + epoxiconazol reduziram $100 \%$ o crescimento dos isolados NU-2 e NU-5. No entanto, essa mesma redução foi observada por trifloxistrobina + protioconazol no isolado NU-2 e por azoxistrobina + benzovindiflupir no isolado NU-5.

O formato dos conídios não foi relacionado a sensibilidade aos ingredientes ativos.

Tabela 3. Índice de velocidade de crescimento micelial $\left(\mathrm{cm}^{\mathrm{dia}}{ }^{-1}\right)$ de isolados de Colletotrichum crescidos em meio de cultura batata dextrose ágar com diferentes ingredientes ativos

Table 3. Average mycelial growth rate $\left(\mathrm{cm}^{-d_{a y}}{ }^{-1}\right)$ of Colletotrichum isolates growth on active ingredients amended potato dextrose agar

\begin{tabular}{|c|c|c|c|c|c|c|c|c|c|}
\hline \multirow{2}{*}{ Isolado } & \multicolumn{7}{|c|}{ Ingrediente ativo } & \multirow[b]{2}{*}{ Test. } & \multirow[b]{2}{*}{ Test. } \\
\hline & $\mathrm{Pi}$ & $\mathrm{Az}+\mathrm{Be}$ & $\operatorname{Tr}+\operatorname{Pr}$ & $\mathrm{Ca}$ & $\mathrm{Pi}+\mathrm{Ep}$ & $\mathrm{Fl}+\mathrm{Pi}$ & $\mathrm{Az}+\mathrm{Ci}$ & & \\
\hline BG-1 & $0,24 \mathrm{bC}$ & $0,00 \mathrm{aA}$ & $0,16 \mathrm{bC}$ & $0,00 \mathrm{aA}$ & $0,00 \mathrm{aA}$ & $0,00 \mathrm{aA}$ & $0,00 \mathrm{aA}$ & $0,60 \mathrm{cC}$ & $0,67 \mathrm{cE}$ \\
\hline $\mathrm{CH}-3$ & $0,11 \mathrm{bB}$ & $0,00 \mathrm{aA}$ & $0,26 \mathrm{cD}$ & $0,31 \mathrm{cD}$ & $0,12 \mathrm{bB}$ & $0,19 \mathrm{bB}$ & $0,23 \mathrm{cB}$ & $0,49 \mathrm{~dB}$ & $0,24 \mathrm{cA}$ \\
\hline CJ-1 & $0,00 \mathrm{aA}$ & $0,05 \mathrm{aA}$ & $0,30 \mathrm{bD}$ & $0,33 \mathrm{bD}$ & $0,00 \mathrm{aA}$ & $0,30 \mathrm{bC}$ & $0,35 \mathrm{bD}$ & $0,52 \mathrm{cC}$ & $0,55 \mathrm{cD}$ \\
\hline CL-5 & $0,22 \mathrm{bC}$ & $0,17 \mathrm{bC}$ & $0,00 \mathrm{aA}$ & $0,47 \mathrm{cE}$ & $0,28 \mathrm{bD}$ & $0,44 \mathrm{cD}$ & $0,21 \mathrm{bB}$ & $0,69 \mathrm{dD}$ & $0,43 \mathrm{cC}$ \\
\hline CL-6 & $0,00 \mathrm{aA}$ & $0,00 \mathrm{aA}$ & $0,00 \mathrm{aA}$ & $0,00 \mathrm{aA}$ & $0,00 \mathrm{aA}$ & $0,00 \mathrm{aA}$ & $0,00 \mathrm{aA}$ & $0,58 \mathrm{cC}$ & $0,50 \mathrm{bC}$ \\
\hline CL-7 & $0,12 \mathrm{aB}$ & $0,30 \mathrm{bD}$ & $0,16 \mathrm{aC}$ & $0,48 \mathrm{cE}$ & $0,15 \mathrm{aB}$ & $0,41 \mathrm{cD}$ & $0,38 \mathrm{cD}$ & $0,42 \mathrm{cB}$ & $0,75 \mathrm{dE}$ \\
\hline $\mathrm{CN}-1$ & $0,00 \mathrm{aA}$ & $0,11 \mathrm{bB}$ & $0,27 \mathrm{cD}$ & $0,13 \mathrm{bB}$ & $0,00 \mathrm{aA}$ & $0,46 \mathrm{dD}$ & $0,33 \mathrm{cD}$ & $0,53 \mathrm{dC}$ & $0,52 \mathrm{dD}$ \\
\hline IN-1 & $0,25 \mathrm{bC}$ & $0,38 \mathrm{cD}$ & $0,00 \mathrm{aA}$ & $0,35 \mathrm{cD}$ & $0,23 \mathrm{bC}$ & $0,52 \mathrm{dE}$ & $0,34 \mathrm{cD}$ & $0,72 \mathrm{eD}$ & $0,72 \mathrm{eE}$ \\
\hline IT-4 & $0,00 \mathrm{aA}$ & $0,00 \mathrm{aA}$ & $0,28 \mathrm{bD}$ & $0,23 \mathrm{bC}$ & $0,00 \mathrm{aA}$ & $0,34 \mathrm{cC}$ & $0,29 \mathrm{bC}$ & $0,34 \mathrm{cA}$ & $0,33 \mathrm{cB}$ \\
\hline IT-6 & $0,00 \mathrm{aA}$ & $0,02 \mathrm{aA}$ & $0,33 \mathrm{cD}$ & $0,16 \mathrm{bB}$ & $0,00 \mathrm{aA}$ & $0,25 \mathrm{cB}$ & $0,28 \mathrm{cC}$ & $0,26 \mathrm{cA}$ & $0,25 \mathrm{cA}$ \\
\hline LU-3 & $0,00 \mathrm{aA}$ & $0,06 \mathrm{aA}$ & $0,29 \mathrm{bD}$ & $0,47 \mathrm{cE}$ & $0,22 \mathrm{bC}$ & $0,30 \mathrm{bC}$ & $0,47 \mathrm{cE}$ & $0,59 \mathrm{dC}$ & $0,43 \mathrm{cC}$ \\
\hline MT-1 & $0,00 \mathrm{aA}$ & $0,00 \mathrm{aA}$ & $0,33 \mathrm{bD}$ & $0,28 \mathrm{bC}$ & $0,00 \mathrm{aA}$ & $0,33 \mathrm{bC}$ & $0,29 \mathrm{bC}$ & $0,31 \mathrm{bA}$ & $0,25 \mathrm{bA}$ \\
\hline NA-1 & $0,24 \mathrm{cC}$ & $0,36 \mathrm{dD}$ & $0,00 \mathrm{aA}$ & $0,67 \mathrm{fF}$ & $0,16 \mathrm{bB}$ & $0,45 \mathrm{eD}$ & $0,29 \mathrm{cC}$ & $0,72 \mathrm{fD}$ & $0,66 \mathrm{fE}$ \\
\hline NB-1 & $0,21 \mathrm{bC}$ & $0,29 \mathrm{cD}$ & $0,00 \mathrm{aA}$ & $0,58 \mathrm{eF}$ & $0,33 \mathrm{cD}$ & $0,34 \mathrm{cC}$ & $0,43 \mathrm{dE}$ & $0,68 \mathrm{fD}$ & $0,58 \mathrm{eD}$ \\
\hline NU-2 & $0,00 \mathrm{aA}$ & $0,26 \mathrm{bC}$ & $0,00 \mathrm{aA}$ & $0,35 \mathrm{cD}$ & $0,00 \mathrm{aA}$ & $0,53 \mathrm{dE}$ & $0,20 \mathrm{bB}$ & $0,64 \mathrm{eD}$ & $0,69 \mathrm{eE}$ \\
\hline NU-5 & $0,00 \mathrm{aA}$ & $0,00 \mathrm{aA}$ & $0,23 \mathrm{bC}$ & $0,31 \mathrm{bD}$ & $0,00 \mathrm{aA}$ & $0,26 \mathrm{bB}$ & $0,29 \mathrm{bC}$ & $0,48 \mathrm{cB}$ & $0,43 \mathrm{cC}$ \\
\hline NX-1 & $0,00 \mathrm{aA}$ & $0,15 \mathrm{bB}$ & $0,33 \mathrm{cD}$ & $0,23 \mathrm{cC}$ & $0,00 \mathrm{aA}$ & $0,26 \mathrm{cB}$ & $0,28 \mathrm{cC}$ & $0,45 \mathrm{~dB}$ & $0,47 \mathrm{dC}$ \\
\hline PE-4 & $0,15 \mathrm{bB}$ & $0,25 \mathrm{bC}$ & $0,00 \mathrm{aA}$ & $0,52 \mathrm{dE}$ & $0,20 \mathrm{bB}$ & $0,40 \mathrm{cD}$ & $0,42 \mathrm{cE}$ & $0,66 \mathrm{eD}$ & $0,74 \mathrm{fE}$ \\
\hline PN-1 & $0,00 \mathrm{aA}$ & $0,16 \mathrm{bB}$ & $0,27 \mathrm{cD}$ & $0,25 \mathrm{cC}$ & $0,00 \mathrm{aA}$ & $0,22 \mathrm{cB}$ & $0,39 \mathrm{dD}$ & $0,36 \mathrm{dA}$ & $0,33 \mathrm{~dB}$ \\
\hline QU-2 & $0,00 \mathrm{aA}$ & $0,00 \mathrm{aA}$ & $0,22 \mathrm{bC}$ & $0,27 \mathrm{bC}$ & $0,00 \mathrm{aA}$ & $0,33 \mathrm{cC}$ & $0,34 \mathrm{cD}$ & $0,41 \mathrm{cB}$ & $0,35 \mathrm{cB}$ \\
\hline RO-1 & $0,14 \mathrm{aB}$ & $0,36 \mathrm{bD}$ & $0,10 \mathrm{aB}$ & $0,31 \mathrm{bD}$ & $0,18 \mathrm{aB}$ & $0,40 \mathrm{bD}$ & $0,35 \mathrm{bD}$ & $0,73 \mathrm{cD}$ & $0,75 \mathrm{cE}$ \\
\hline SC-1 & $0,16 \mathrm{bB}$ & $0,00 \mathrm{aA}$ & $0,34 \mathrm{cD}$ & $0,00 \mathrm{aA}$ & $0,00 \mathrm{aA}$ & $0,32 \mathrm{cC}$ & $0,30 \mathrm{cC}$ & $0,44 \mathrm{~dB}$ & $0,44 \mathrm{dC}$ \\
\hline SI-3 & $0,00 \mathrm{aA}$ & $0,20 \mathrm{bC}$ & $0,00 \mathrm{aA}$ & $0,64 \mathrm{dF}$ & $0,00 \mathrm{aA}$ & $0,40 \mathrm{cD}$ & $0,22 \mathrm{bB}$ & $0,68 \mathrm{dD}$ & $0,70 \mathrm{dE}$ \\
\hline SO-5 & $0,11 \mathrm{aB}$ & $0,22 \mathrm{bC}$ & $0,09 \mathrm{aB}$ & $0,46 \mathrm{cE}$ & $0,16 \mathrm{aB}$ & $0,42 \mathrm{cD}$ & $0,27 \mathrm{bC}$ & $0,69 \mathrm{dD}$ & $0,73 \mathrm{dE}$ \\
\hline SO-6 & $0,00 \mathrm{aA}$ & $0,00 \mathrm{aA}$ & $0,17 \mathrm{bC}$ & $0,00 \mathrm{aA}$ & $0,00 \mathrm{aA}$ & $0,19 \mathrm{bB}$ & $0,05 \mathrm{aA}$ & $0,42 \mathrm{cB}$ & $0,35 \mathrm{cB}$ \\
\hline SO-9 & $0,15 \mathrm{bB}$ & $0,00 \mathrm{aA}$ & $0,17 \mathrm{bC}$ & $0,12 \mathrm{bB}$ & $0,00 \mathrm{aA}$ & $0,00 \mathrm{aA}$ & $0,00 \mathrm{aA}$ & $0,68 \mathrm{cD}$ & $0,69 \mathrm{cE}$ \\
\hline SO-11 & $0,00 \mathrm{aA}$ & $0,12 \mathrm{bB}$ & $0,30 \mathrm{cD}$ & $0,15 \mathrm{bB}$ & $0,00 \mathrm{aA}$ & $0,29 \mathrm{cC}$ & $0,23 \mathrm{cB}$ & $0,32 \mathrm{cA}$ & $0,34 \mathrm{cB}$ \\
\hline TB-2 & $0,00 \mathrm{aA}$ & $0,11 \mathrm{bB}$ & $0,28 \mathrm{cD}$ & $0,23 \mathrm{cC}$ & $0,00 \mathrm{aA}$ & $0,25 \mathrm{cB}$ & $0,27 \mathrm{cC}$ & $0,32 \mathrm{dA}$ & $0,36 \mathrm{~dB}$ \\
\hline VE-5 & $0,00 \mathrm{aA}$ & $0,00 \mathrm{aA}$ & $0,28 \mathrm{cD}$ & $0,24 \mathrm{bC}$ & $0,00 \mathrm{aA}$ & $0,21 \mathrm{bB}$ & $0,31 \mathrm{cC}$ & $0,34 \mathrm{cA}$ & $0,29 \mathrm{cA}$ \\
\hline VR-1 & $0,00 \mathrm{aA}$ & $0,11 \mathrm{bB}$ & $0,31 \mathrm{cD}$ & $0,07 \mathrm{bB}$ & $0,00 \mathrm{aA}$ & $0,27 \mathrm{cB}$ & $0,25 \mathrm{cB}$ & $0,31 \mathrm{cA}$ & $0,27 \mathrm{cA}$ \\
\hline
\end{tabular}

Médias seguidas de mesma letra minúscula na linha e letras maiúsculas na coluna não diferem entre si pelo teste de Scott-Knott a $5 \%$ de significância. $\mathrm{Az}=$ azoxistrobina, $\mathrm{Be}=$ benzovindiflupir, $\mathrm{Ca}=$ carbendazim, $\mathrm{Ci}=$ ciproconazol, $\mathrm{Ep}=$ epoxiconazol, $\mathrm{Fl}=$ fluxapiroxade, $\mathrm{Pi}=$ piraclostrobina, $\mathrm{Pr}=$ protioconazol $\mathrm{e}$ $\operatorname{Tr}=$ trifloxistrobina.

\subsection{Reação de cultivares de soja a antracnose}

As sementes inoculadas apresentaram sintomas de antracnose, confirmando a patogenicidade dos 27 isolados testados. $\mathrm{Na}$ testemunha, as sementes apresentaram-se isentas do patógeno.

\subsubsection{Tombamento}

Houve interação significativa entre isolados e cultivares estudadas (Tabela 4). O menor número de tombamento pré ou pós emergência foi observado em todas as cultivares inoculadas com os isolados CL-5, CL-6, CL-7, NA-1, NB-1, NU-2, NX-1, PE-4, RO-1 e SI-3. E desses isolados 70\% apresentam conídios cilíndrico. A baixa porcentagem de tombamento também foi observada nos isolados: CJ-1, exceto nas cultivares 1179 e 9144; IN-1, exceto para cultivar 9144; e IT-6, exceto para cultivar 1179.

Isolados LU-3, NU-5, PN-1, QU-2, VR-1 e SO-11 foram altamente agressivos em todas as cultivares, exceto o isolado SO-11 quando inoculado na cultivar 3820. Esses isolados possuem os conídios em formato clavado, exceto o isolado QU-2, o qual possui conídio fusiforme.

Os isolados IT-4 e IT-6 ocasionaram 100\% de tombamento na cultivar 1179. O elevado tombamento também foi observado nas cultivares 8866 e 1179, na presença do isolado TB-2. A morfologia dos conídios desses isolados são em formato clavado.

As cultivares 8866 convencional, 1179 RR e 9144 RR apresentaram maior suscetibilidade ao patógeno. Sendo o 
tombamento das plântulas igual ou superior a 75\% para 9,11 e 9 isolados dos 27 inoculados, respectivamente.

Tabela 4. Incidência em porcentagem de tombamento pré e pósemergente de cultivares de soja inoculadas com Colletotrichum.

Table 4. Incidence in percentage of pre and post-emergence damping-off in soybean cultivars inoculated with isolates of Colletotrichum.

\begin{tabular}{|c|c|c|c|c|c|c|}
\hline \multirow{2}{*}{ Isolado } & \multicolumn{6}{|c|}{ Cultivar } \\
\hline & 3820 & 1188 & 132 & 8866 & 1179 & 9144 \\
\hline \multirow{2}{*}{ CH-3 } & 8 & 0 & 8 & 33 & 75 & 83 \\
\hline & $\mathrm{aA}$ & $\mathrm{aA}$ & $\mathrm{aA}$ & bB & $\mathrm{cC}$ & $\mathrm{cD}$ \\
\hline \multirow{2}{*}{ CJ-1 } & 0 & 0 & 0 & 25 & 66 & 58 \\
\hline & $\mathrm{aA}$ & $\mathrm{aA}$ & $\mathrm{aA}$ & bB & $\mathrm{cC}$ & $\mathrm{cC}$ \\
\hline \multirow{2}{*}{ CL-5 } & 0 & 0 & 0 & 0 & 8 & 8 \\
\hline & $\mathrm{aA}$ & $\mathrm{aA}$ & $\mathrm{aA}$ & $\mathrm{aA}$ & $\mathrm{aA}$ & $\mathrm{aA}$ \\
\hline \multirow{2}{*}{ CL-6 } & 16 & 0 & 0 & 16 & 8 & 0 \\
\hline & $\mathrm{aA}$ & $\mathrm{aA}$ & $\mathrm{aA}$ & $\mathrm{aA}$ & $\mathrm{aA}$ & $\mathrm{aA}$ \\
\hline \multirow{2}{*}{ CL-7 } & 0 & 0 & 0 & 16 & 0 & 0 \\
\hline & $\mathrm{aA}$ & $\mathrm{aA}$ & $\mathrm{aA}$ & aA & $\mathrm{aA}$ & $\mathrm{aA}$ \\
\hline \multirow{2}{*}{ IN-1 } & 8 & 0 & 0 & 33 & 16 & 83 \\
\hline & $\mathrm{aA}$ & $\mathrm{aA}$ & $\mathrm{aA}$ & $\mathrm{bB}$ & $\mathrm{bA}$ & $\mathrm{cD}$ \\
\hline \multirow{2}{*}{ IT-4 } & 66 & 50 & 83 & 91 & 100 & 41 \\
\hline & $\mathrm{aC}$ & $\mathrm{aB}$ & $\mathrm{bC}$ & $\mathrm{bC}$ & $\mathrm{bD}$ & $\mathrm{aB}$ \\
\hline \multirow{2}{*}{ IT-6 } & 8 & 0 & 66 & 16 & 100 & 0 \\
\hline & $\mathrm{aA}$ & $\mathrm{aA}$ & $\mathrm{bB}$ & $\mathrm{aA}$ & $\mathrm{cD}$ & $\mathrm{aA}$ \\
\hline \multirow{2}{*}{ LU-3 } & 100 & 100 & 100 & 100 & 100 & 100 \\
\hline & $\mathrm{aD}$ & $\mathrm{aC}$ & $\mathrm{aC}$ & $\mathrm{aC}$ & $\mathrm{aD}$ & $\mathrm{aD}$ \\
\hline \multirow{2}{*}{ MT-1 } & 8 & 8 & 8 & 25 & 41 & 50 \\
\hline & $\mathrm{aA}$ & $\mathrm{aA}$ & $\mathrm{aA}$ & $\mathrm{aB}$ & $\mathrm{bB}$ & $\mathrm{bC}$ \\
\hline \multirow{2}{*}{ NA-1 } & 8 & 0 & 0 & 16 & 8 & 16 \\
\hline & $\mathrm{aA}$ & $\mathrm{aA}$ & $\mathrm{aA}$ & $\mathrm{aA}$ & $\mathrm{aA}$ & $\mathrm{aA}$ \\
\hline \multirow{2}{*}{ NB-1 } & 0 & 0 & 0 & 0 & 0 & 0 \\
\hline & aA & aA & aA & $\mathrm{aA}$ & $\mathrm{aA}$ & $\mathrm{aA}$ \\
\hline \multirow{2}{*}{ NU-2 } & 0 & 0 & 8 & 16 & 8 & 8 \\
\hline & $\mathrm{aA}$ & $\mathrm{aA}$ & aA & $\mathrm{aA}$ & $\mathrm{aA}$ & $\mathrm{aA}$ \\
\hline \multirow{2}{*}{ NU-5 } & 75 & 100 & 91 & 100 & 100 & 100 \\
\hline & $\mathrm{aC}$ & $\mathrm{aC}$ & $\mathrm{aC}$ & $\mathrm{aC}$ & $\mathrm{aD}$ & $\mathrm{aD}$ \\
\hline \multirow{2}{*}{ NX-1 } & 0 & 0 & 0 & 0 & 0 & 8 \\
\hline & $\mathrm{aA}$ & $\mathrm{aA}$ & $\mathrm{aA}$ & $\mathrm{aA}$ & $\mathrm{aA}$ & $\mathrm{aA}$ \\
\hline PE-4 & 8 & 0 & 8 & 16 & 0 & 0 \\
\hline PE-4 & $\mathrm{aA}$ & $\mathrm{aA}$ & $\mathrm{aA}$ & $\mathrm{aA}$ & $\mathrm{aA}$ & $\mathrm{aA}$ \\
\hline PN-1 & 100 & 100 & 75 & 100 & 100 & 100 \\
\hline PN-1 & $\mathrm{aD}$ & $\mathrm{aC}$ & $\mathrm{aB}$ & $\mathrm{aC}$ & $\mathrm{aD}$ & $\mathrm{aD}$ \\
\hline & 100 & 100 & 75 & 100 & 100 & 100 \\
\hline QU-2 & $\mathrm{aD}$ & $\mathrm{aC}$ & $\mathrm{aB}$ & $\mathrm{aC}$ & $\mathrm{aD}$ & $\mathrm{aD}$ \\
\hline & 0 & 0 & 0 & 8 & 0 & 0 \\
\hline RO-1 & $\mathrm{aA}$ & $\mathrm{aA}$ & $\mathrm{aA}$ & $\mathrm{aA}$ & $\mathrm{aA}$ & $\mathrm{aA}$ \\
\hline & 0 & 0 & 0 & 41 & 16 & 41 \\
\hline $\mathrm{SC}-1$ & $\mathrm{aA}$ & $\mathrm{aA}$ & $\mathrm{aA}$ & $\mathrm{bB}$ & $\mathrm{aA}$ & $\mathrm{bB}$ \\
\hline & 0 & 0 & 0 & 8 & 8 & 8 \\
\hline SI-3 & $\mathrm{aA}$ & $\mathrm{aA}$ & $\mathrm{aA}$ & $\mathrm{aA}$ & $\mathrm{aA}$ & $\mathrm{aA}$ \\
\hline & 41 & 100 & 91 & 100 & 100 & 100 \\
\hline SO-11 & $\mathrm{aB}$ & $\mathrm{bC}$ & $\mathrm{bC}$ & $\mathrm{bC}$ & $\mathrm{bD}$ & $\mathrm{bD}$ \\
\hline & 0 & 0 & 0 & 16 & 0 & 25 \\
\hline SO-5 & $\mathrm{aA}$ & $\mathrm{aA}$ & $\mathrm{aA}$ & bA & $\mathrm{aA}$ & $\mathrm{bB}$ \\
\hline & 41 & 66 & 25 & 91 & 50 & 75 \\
\hline $50-6$ & $\mathrm{aB}$ & bB & $\mathrm{aA}$ & $\mathrm{bC}$ & $\mathrm{aB}$ & $\mathrm{bC}$ \\
\hline & 25 & 58 & 25 & 100 & 100 & 66 \\
\hline TB-2 & $\mathrm{aB}$ & $\mathrm{bB}$ & $\mathrm{aA}$ & $\mathrm{cC}$ & $\mathrm{cD}$ & $\mathrm{bC}$ \\
\hline & 41 & 75 & 66 & 50 & 75 & 50 \\
\hline VE-5 & $\mathrm{aB}$ & bB & bB & $\mathrm{aB}$ & $\mathrm{bC}$ & $\mathrm{aC}$ \\
\hline & 100 & 91 & 91 & 100 & 100 & 91 \\
\hline VR-1 & $\mathrm{aD}$ & $\mathrm{aC}$ & $\mathrm{aC}$ & $\mathrm{aC}$ & $\mathrm{aD}$ & $\mathrm{aD}$ \\
\hline Test. & 0 & 0 & 0 & 0 & 0 & 0 \\
\hline I est. & $\mathrm{aA}$ & $\mathrm{aA}$ & $\mathrm{aA}$ & $\mathrm{aA}$ & $\mathrm{aA}$ & $\mathrm{aA}$ \\
\hline
\end{tabular}

Médias seguidas de mesma letra minúscula na linha e letras maiúsculas na coluna não diferem entre si pelo teste de Scott-Knott a 5\% de significância.
3.2.2. Área Abaixo da Curva de Progresso da Incidência (AACPI) e Severidade (AACPS)

Houve interação significativa entre isolados e cultivares para AACPI e AACPS (Tabela 5 e 6 ).

Tabela 5. Área abaixo da curva do progresso da incidência (AACPI) para cultivares de soja inoculadas com 27 isolados de Colletotrichum. Table 5. Area under the incidence progress curve (AUIPC) in the soybean cultivars inoculated with 27 isolates of Colletotrichum.

\begin{tabular}{|c|c|c|c|c|c|c|}
\hline \multirow{2}{*}{ Isolado } & \multicolumn{6}{|c|}{ Cultivar } \\
\hline & 3820 & 1188 & 132 & 8866 & 1179 & 9144 \\
\hline \multirow{2}{*}{ CH-3 } & 1,33 & 1,33 & 2,16 & 6,66 & 12,00 & 16,00 \\
\hline & $\mathrm{aA}$ & $\mathrm{aA}$ & $\mathrm{aB}$ & $\mathrm{bB}$ & $\mathrm{cD}$ & $\mathrm{dD}$ \\
\hline \multirow{2}{*}{ CJ-1 } & 0,00 & 2,66 & 4,00 & 5,33 & 13,33 & 10,16 \\
\hline & $\mathrm{aA}$ & $\mathrm{bB}$ & $\mathrm{bB}$ & $\mathrm{bB}$ & $\mathrm{cD}$ & $\mathrm{cB}$ \\
\hline \multirow{2}{*}{ CL-5 } & 2,16 & 5,33 & 0,00 & 6,66 & 7,16 & 1,33 \\
\hline & $\mathrm{aA}$ & $\mathrm{bB}$ & $\mathrm{aA}$ & $\mathrm{bB}$ & $\mathrm{bC}$ & $\mathrm{aA}$ \\
\hline \multirow{2}{*}{ CL-6 } & 3,83 & 0,00 & 2,16 & 2,66 & 1,83 & 0,00 \\
\hline & $\mathrm{aA}$ & $\mathrm{aA}$ & $\mathrm{aB}$ & $\mathrm{aA}$ & $\mathrm{aA}$ & $\mathrm{aA}$ \\
\hline \multirow{2}{*}{ CL-7 } & 0,00 & 0,00 & 0,00 & 2,86 & 0,00 & 0,00 \\
\hline & $\mathrm{aA}$ & $\mathrm{aA}$ & $\mathrm{aA}$ & $\mathrm{aA}$ & $\mathrm{aA}$ & $\mathrm{aA}$ \\
\hline \multirow{2}{*}{ IN-1 } & 16,00 & 0,00 & 0,00 & 2,66 & 2,66 & 0,00 \\
\hline & $\mathrm{bC}$ & $\mathrm{aA}$ & $\mathrm{aA}$ & $\mathrm{aA}$ & $\mathrm{aB}$ & $\mathrm{aA}$ \\
\hline \multirow{2}{*}{ IT-4 } & 16,00 & 16,00 & 16,00 & 16,00 & 16,00 & 16,00 \\
\hline & $\mathrm{aC}$ & $\mathrm{aE}$ & $\mathrm{aD}$ & $\mathrm{aD}$ & $\mathrm{aE}$ & $\mathrm{aD}$ \\
\hline \multirow{2}{*}{ IT-6 } & 16,00 & 16,00 & 16,00 & 16,00 & 16,00 & 16,00 \\
\hline & $\mathrm{aC}$ & $\mathrm{aE}$ & $\mathrm{aD}$ & $\mathrm{aD}$ & $\mathrm{aE}$ & $\mathrm{aD}$ \\
\hline \multirow{2}{*}{ LU-3 } & 16,00 & 16,00 & 16,00 & 16,00 & 16,00 & 16,00 \\
\hline & $\mathrm{aC}$ & $\mathrm{aE}$ & $\mathrm{aD}$ & $\mathrm{aD}$ & $\mathrm{aE}$ & $\mathrm{aD}$ \\
\hline \multirow{2}{*}{ MT-1 } & 10,66 & 10,66 & 12,00 & 10,66 & 13,16 & 9,33 \\
\hline & $\mathrm{aB}$ & $\mathrm{aD}$ & $\mathrm{aC}$ & $\mathrm{aC}$ & $\mathrm{aD}$ & $\mathrm{aB}$ \\
\hline \multirow{2}{*}{ NA-1 } & 1,33 & 0,00 & 0,00 & 2,66 & 1,83 & 3,83 \\
\hline & $\mathrm{aA}$ & $\mathrm{aA}$ & $\mathrm{aA}$ & $\mathrm{aA}$ & $\mathrm{aA}$ & $\mathrm{aA}$ \\
\hline \multirow{2}{*}{ NB-1 } & 0,00 & 0,00 & 0,00 & 0,00 & 0,00 & 1,33 \\
\hline & $\mathrm{aA}$ & $\mathrm{aA}$ & $\mathrm{aA}$ & $\mathrm{aA}$ & $\mathrm{aA}$ & $\mathrm{aA}$ \\
\hline \multirow{2}{*}{ NU-2 } & 0,00 & 3,83 & 3,33 & 2,66 & 2,66 & 1,33 \\
\hline & $\mathrm{aA}$ & $\mathrm{aB}$ & $\mathrm{aB}$ & $\mathrm{aA}$ & $\mathrm{aB}$ & $\mathrm{aA}$ \\
\hline \multirow{2}{*}{ NU-5 } & 16,00 & 16,00 & 16,00 & 16,00 & 16,00 & 16,00 \\
\hline & $\mathrm{aC}$ & $\mathrm{aE}$ & $\mathrm{aD}$ & $\mathrm{aD}$ & $\mathrm{aE}$ & $\mathrm{aD}$ \\
\hline \multirow{2}{*}{ NX-1 } & 0,00 & 0,00 & 0,00 & 0,00 & 0,00 & 1,33 \\
\hline & $\mathrm{aA}$ & $\mathrm{aA}$ & $\mathrm{aA}$ & $\mathrm{aA}$ & $\mathrm{aA}$ & $\mathrm{aA}$ \\
\hline PF 4 & 2,50 & 3,33 & 4,33 & 3,83 & 0,83 & 1,33 \\
\hline 1 E-4 & $\mathrm{aA}$ & $\mathrm{aB}$ & $\mathrm{aB}$ & $\mathrm{aA}$ & $\mathrm{aA}$ & $\mathrm{aA}$ \\
\hline PN-1 & 16,00 & 16,00 & 16,00 & 16,00 & 16,00 & 16,00 \\
\hline PN-I & $\mathrm{aC}$ & $\mathrm{aE}$ & $\mathrm{aD}$ & $\mathrm{aD}$ & $\mathrm{aE}$ & $\mathrm{aD}$ \\
\hline OL $?$ & 16,00 & 16,00 & 15,66 & 16,00 & 16,00 & 16,00 \\
\hline QU-2 & $\mathrm{aC}$ & $\mathrm{aE}$ & $\mathrm{aD}$ & $\mathrm{aD}$ & $\mathrm{aE}$ & $\mathrm{aD}$ \\
\hline RO-1 & 3,66 & 8,00 & 0,00 & 5,33 & 3,50 & 2,00 \\
\hline KU-1 & $\mathrm{aA}$ & $\mathrm{bC}$ & $\mathrm{aA}$ & $\mathrm{bB}$ & $\mathrm{aB}$ & $\mathrm{aA}$ \\
\hline$S C-1$ & 0,00 & 4,00 & 2,66 & 6,66 & 10,50 & 9,33 \\
\hline $\operatorname{sc-1}$ & $\mathrm{aA}$ & $\mathrm{aB}$ & $\mathrm{aB}$ & $\mathrm{bB}$ & $\mathrm{bD}$ & $\mathrm{bB}$ \\
\hline $\mathrm{SL}_{3}$ & 0,00 & 0,50 & 1,00 & 1,33 & 3,83 & 2,66 \\
\hline $51-3$ & $\mathrm{aA}$ & $\mathrm{aA}$ & $\mathrm{aA}$ & $\mathrm{aA}$ & $\mathrm{aB}$ & $\mathrm{aA}$ \\
\hline$S \cap 11$ & 11,83 & 16,00 & 16,00 & 16,00 & 16,00 & 16,00 \\
\hline $50-11$ & $\mathrm{aB}$ & $\mathrm{bE}$ & bD & bD & $\mathrm{bE}$ & bD \\
\hline$S O 5$ & 0,00 & 0,00 & 0,00 & 2,66 & 0,00 & 4,00 \\
\hline $50-5$ & $\mathrm{aA}$ & $\mathrm{aA}$ & $\mathrm{aA}$ & $\mathrm{bA}$ & $\mathrm{aA}$ & bA \\
\hline $\mathrm{SO}$ & 9,33 & 13,33 & 7,16 & 16,00 & 16,00 & 13,33 \\
\hline $50-0$ & $\mathrm{aB}$ & $\mathrm{bD}$ & $\mathrm{aB}$ & $\mathrm{bD}$ & $\mathrm{bE}$ & $\mathrm{bC}$ \\
\hline TB_2 & 10,33 & 12,00 & 11,50 & 16,00 & 16,00 & 13,00 \\
\hline $1 \mathrm{D}-2$ & $\mathrm{aB}$ & $\mathrm{aD}$ & $\mathrm{aC}$ & bD & $\mathrm{bE}$ & $\mathrm{aC}$ \\
\hline 5 & 10,66 & 16,00 & 16,00 & 9,33 & 16,00 & 12,00 \\
\hline$\sqrt{ } \mathrm{E}-5$ & $\mathrm{aB}$ & $\mathrm{bE}$ & bD & $\mathrm{aB}$ & $\mathrm{bE}$ & $\mathrm{aC}$ \\
\hline VR 1 & 16,00 & 16,00 & 16,00 & 16,00 & 16,00 & 16,00 \\
\hline VR-1 & $\mathrm{aC}$ & $\mathrm{aE}$ & $\mathrm{aD}$ & $\mathrm{aD}$ & $\mathrm{aE}$ & $\mathrm{aD}$ \\
\hline Test & 0,00 & 0,00 & 0,00 & 0,00 & 0,00 & 0,00 \\
\hline 1 est. & $\mathrm{aA}$ & $\mathrm{aA}$ & $\mathrm{aA}$ & $\mathrm{aA}$ & $\mathrm{aA}$ & $\mathrm{aA}$ \\
\hline
\end{tabular}


Tabela 6. Area abaixo da curva de progresso da severidade (AACPS) para cultivares de soja inoculadas com 27 isolados de Colletotrichum.

Table 6 . Area under the severity progress curve (AUSPC) in the soybean cultivars inoculated with 27 isolates of Colletotrichum.

\begin{tabular}{|c|c|c|c|c|c|c|}
\hline \multirow{2}{*}{ Isolado } & \multicolumn{6}{|c|}{ Cultivar } \\
\hline & 3820 & 1188 & 132 & 8866 & 1179 & 9144 \\
\hline \multirow{2}{*}{$\mathrm{CH}-3$} & 0,00 & 7,61 & 14,58 & 58,28 & 120,0 & 149,8 \\
\hline & $\mathrm{aA}$ & $\mathrm{aA}$ & $\mathrm{aA}$ & $\mathrm{Bc}$ & $\mathrm{cC}$ & $\mathrm{cC}$ \\
\hline \multirow{2}{*}{ CJ-1 } & 0,00 & 11,95 & 17,71 & 42,00 & 122,5 & 97,6 \\
\hline & $\mathrm{aA}$ & $\mathrm{aA}$ & $\mathrm{aA}$ & $\mathrm{bB}$ & $\mathrm{cC}$ & $\mathrm{cB}$ \\
\hline \multirow{2}{*}{ CL-5 } & 13,42 & 31,83 & 0,00 & 34,78 & 49,66 & 13,3 \\
\hline & $\mathrm{aA}$ & bB & $\mathrm{aA}$ & bB & bB & $\mathrm{aA}$ \\
\hline \multirow{2}{*}{ CL-6 } & 32,20 & 0,00 & 11,78 & 26,66 & 18,33 & 0,00 \\
\hline & $\mathrm{aB}$ & $\mathrm{aA}$ & $\mathrm{aA}$ & $\mathrm{aB}$ & $\mathrm{aA}$ & $\mathrm{aA}$ \\
\hline \multirow{2}{*}{ CL-7 } & 0,00 & 0,00 & 0,00 & 26,66 & 0,00 & 0,00 \\
\hline & $\mathrm{aA}$ & $\mathrm{aA}$ & $\mathrm{aA}$ & $\mathrm{aB}$ & $\mathrm{aA}$ & $\mathrm{aA}$ \\
\hline \multirow{2}{*}{ IN-1 } & 13,33 & 0,00 & 0,00 & 26,66 & 26,66 & 0,00 \\
\hline & $\mathrm{aA}$ & $\mathrm{aA}$ & $\mathrm{aA}$ & $\mathrm{aB}$ & $\mathrm{aA}$ & $\mathrm{aA}$ \\
\hline \multirow{2}{*}{ IT-4 } & 130,4 & 128,7 & 149,6 & 159,0 & 160,0 & 138,4 \\
\hline & $\mathrm{aE}$ & $\mathrm{aC}$ & $\mathrm{aD}$ & $\mathrm{aD}$ & $\mathrm{aD}$ & $\mathrm{aC}$ \\
\hline \multirow{2}{*}{ IT-6 } & 160,0 & 153,2 & 134,5 & 160,0 & 160,0 & 160,0 \\
\hline & $\mathrm{aE}$ & $\mathrm{aD}$ & $\mathrm{aC}$ & $\mathrm{aD}$ & $\mathrm{aD}$ & $\mathrm{aC}$ \\
\hline \multirow{2}{*}{ LU-3 } & 160,0 & 160,0 & 160,0 & 160,0 & 160,0 & 160,0 \\
\hline & $\mathrm{aE}$ & $\mathrm{aD}$ & $\mathrm{aD}$ & $\mathrm{aD}$ & $\mathrm{aD}$ & $\mathrm{aC}$ \\
\hline \multirow{2}{*}{ MT-1 } & 64,03 & 70,11 & 76,35 & 77,28 & 119,9 & 87,8 \\
\hline & $\mathrm{aC}$ & $\mathrm{aB}$ & $\mathrm{aA}$ & $\mathrm{aC}$ & $\mathrm{bC}$ & $\mathrm{aB}$ \\
\hline \multirow{2}{*}{ NA-1 } & 13,33 & 0,00 & 3,05 & 26,6 & 15,8 & 33,3 \\
\hline & $\mathrm{aA}$ & $\mathrm{aA}$ & $\mathrm{aA}$ & $\mathrm{aB}$ & $\mathrm{aA}$ & $\mathrm{aA}$ \\
\hline \multirow{2}{*}{ NB-1 } & 0,00 & 0,00 & 0,00 & 0,00 & 0,00 & 13,3 \\
\hline & $\mathrm{aA}$ & $\mathrm{aA}$ & $\mathrm{aA}$ & $\mathrm{aA}$ & $\mathrm{aA}$ & $\mathrm{aA}$ \\
\hline \multirow{2}{*}{ NU-2 } & 0,00 & 18,8 & 23,1 & 26,6 & 18,8 & 13,3 \\
\hline & $\mathrm{aA}$ & $\mathrm{aA}$ & $\mathrm{aA}$ & $\mathrm{aB}$ & $\mathrm{aA}$ & $\mathrm{aA}$ \\
\hline \multirow{2}{*}{ NU-5 } & 152,3 & 160,0 & 158,5 & 160,0 & 160,0 & 160,0 \\
\hline & $\mathrm{aE}$ & $\mathrm{aD}$ & $\mathrm{aD}$ & $\mathrm{aD}$ & $\mathrm{aD}$ & $\mathrm{aC}$ \\
\hline \multirow{2}{*}{ NX-1 } & 0,00 & 0,00 & 0,00 & 0,00 & 0,00 & 13,3 \\
\hline & $\mathrm{aA}$ & $\mathrm{aA}$ & $\mathrm{aA}$ & $\mathrm{Aa}$ & $\mathrm{aA}$ & $\mathrm{aA}$ \\
\hline & 20,1 & 16,6 & 26,2 & 32,4 & 3,75 & 8,05 \\
\hline PE-4 & $\mathrm{aA}$ & $\mathrm{aA}$ & $\mathrm{aA}$ & $\mathrm{aB}$ & $\mathrm{aA}$ & $\mathrm{aA}$ \\
\hline & 160,0 & 157,5 & 147,3 & 160,0 & 160,0 & 160,0 \\
\hline PN-1 & $\mathrm{aE}$ & $\mathrm{aD}$ & $\mathrm{aD}$ & $\mathrm{aD}$ & $\mathrm{aD}$ & $\mathrm{aC}$ \\
\hline & 160,0 & 160,0 & 140,4 & 160,0 & 160,0 & 160,0 \\
\hline QU-2 & $\mathrm{aE}$ & $\mathrm{aD}$ & $\mathrm{aC}$ & $\mathrm{aD}$ & $\mathrm{aD}$ & $\mathrm{aC}$ \\
\hline & 19,5 & 47,6 & 0,00 & 32,3 & 12,7 & 7,66 \\
\hline $\mathrm{RO}-1$ & $\mathrm{aA}$ & $\mathrm{bB}$ & $\mathrm{aA}$ & $\mathrm{bB}$ & $\mathrm{aA}$ & $\mathrm{aA}$ \\
\hline$S C 1$ & 0,00 & 21,60 & 14,28 & 42,0 & 71,1 & 80,9 \\
\hline SC-1 & $\mathrm{aA}$ & $\mathrm{aA}$ & $\mathrm{aA}$ & $\mathrm{aB}$ & $\mathrm{bB}$ & $\mathrm{bB}$ \\
\hline & 0,00 & 2,20 & 5,65 & 13,3 & 24,1 & 26,6 \\
\hline SI-3 & $\mathrm{aA}$ & $\mathrm{aA}$ & $\mathrm{aA}$ & $\mathrm{aA}$ & $\mathrm{aA}$ & $\mathrm{aA}$ \\
\hline & 115,3 & 160,0 & 154,1 & 160,0 & 160,0 & 160,0 \\
\hline SO-11 & $\mathrm{aD}$ & bD & bD & bD & $\mathrm{bD}$ & $\mathrm{bC}$ \\
\hline$S O 5$ & 0,00 & 0,00 & 0,00 & 26,6 & 0,00 & 40,0 \\
\hline $50-5$ & $\mathrm{aA}$ & $\mathrm{aA}$ & $\mathrm{aA}$ & $\mathrm{bB}$ & $\mathrm{aA}$ & $\mathrm{bA}$ \\
\hline & 80,3 & 119,6 & 56,5 & 154,2 & 128,3 & 125,9 \\
\hline $50-6$ & $\mathrm{aD}$ & $\mathrm{bC}$ & $\mathrm{aB}$ & bD & $\mathrm{bC}$ & $\mathrm{bC}$ \\
\hline TP? & 96,31 & 112,1 & 108,6 & 160,0 & 160,0 & 130,0 \\
\hline $1 \mathrm{~B}-2$ & $\mathrm{aD}$ & $\mathrm{aC}$ & $\mathrm{aC}$ & bD & bD & $\mathrm{aC}$ \\
\hline & 89,26 & 139,8 & 134,7 & 87,8 & 151,5 & 99,8 \\
\hline$V E-5$ & $\mathrm{aD}$ & bD & bC & $\mathrm{aC}$ & bD & $\mathrm{aB}$ \\
\hline VP 1 & 160,0 & 158,5 & 157,5 & 160,0 & 160,0 & 153,5 \\
\hline$V K-1$ & $\mathrm{aE}$ & $\mathrm{aD}$ & $\mathrm{aD}$ & $\mathrm{aD}$ & $\mathrm{aD}$ & $\mathrm{aC}$ \\
\hline & 0,00 & 0,00 & 0,00 & 0,00 & 0,00 & 0,00 \\
\hline Test. & $\mathrm{aA}$ & $\mathrm{aA}$ & $\mathrm{aA}$ & $\mathrm{aA}$ & $\mathrm{aA}$ & $\mathrm{aA}$ \\
\hline
\end{tabular}

Médias seguidas de mesma letra minúscula na linha e letras maiúsculas
coluna não diferem entre si pelo teste Scott-Knott a $5 \%$ de significância.

Os isolados CL-6, CL-7, NA-1, NB-1, NU-2, NX-1, PE4 e SI-3 não apresentaram diferenças entre as 6 cultivares de soja, sendo as menores AACPI e AACPS. Os isolados IT-4, IT-6, LU-3, MT-1, NU-5, PN-1, QU-2, e VR-1 não apresentaram diferença entre cultivares, entretanto, foram os mais agressivos com elevada AACPI e AACPS. O mesmo aconteceu com os isolados: SO-11, exceto para a cultivar
3820; SO-6, exceto para as cultivares 3820 e 132; e VE-5, exceto para as cultivares 3820 e 8866 .

Com exceção do isolado QU-2, os isolados mais agressivos possuem formato clavado do conídio.

Corroborando com os dados de tombamento, as cultivares 3820 convencional, 1188 RR e 132 RR apresentaram maior resistência aos isolados quando comparada com as demais cultivares. Estas possuem maior número de isolados com menores índices de incidência e severidade.

\section{DISCUSSÃO}

No presente estudo, isolados de Colletotrichum se diferenciaram quanto a sensibilidade aos ingredientes ativos com diferentes modos de ação. Corroborando com os nossos resultados os isolados de $C$. truncatum foram classificados em suscetível, moderadamente resistente e altamente resistente quanto a ação do thiabendazole, mancozeb, azoxistrobina e cyprodinil + fludioxonil (TORRES-CALZADA et al., 2015). Segundo os autores o local de origem dos isolados não influenciou essa classificação. Entretanto, os níveis de resistência ou sensibilidade de isolados podem estar relacionados ao uso constante de fungicidas durante o período de cultivo da soja, sugerindo pressão de seleção (LOPES et al., 2015).

Por outro lado, em estudos realizados com isolados de $C$. acutatum e C. gloeosporioides, provenientes de diferentes municípios do estado de São Paulo, a ação do piraclostrobina (estrobilurina) foi eficiente no controle da antracnose, porém influenciada pelo isolado e localidade (FISCHER et al., 2012).

A mistura de ingredientes ativos na cultura da soja potencializa o modo de ação e reduz do risco de seleção de populações resistentes a antracnose, destacando-se a combinação dos grupos químicos estrobilurinas e triazóis (SOUZA, 2009). Em campos de produção de soja do Norte do Brasil a combinação de piraclostrobina +epoxiconazol (estrobilurinas+triazóis) não foi eficiente na redução da intensidade da antracnose, discordando dos resultados obtidos no presente trabalho. Por outro lado, a menor incidência nas vagens foi verificada nas parcelas pulverizadas com azoxistrobina + ciproconazol (estrobilurinas+triazóis) (DIAS et al., 2016). Dessa forma, os autores descrevem que o controle da antracnose não deve ser baseado apenas na aplicação de fungicidas, mas sim na integração de práticas agrícolas.

As cultivares que apresentaram maior suscetibilidade a doença são as mais utilizadas nos campos de produção do estado do Mato Grosso, motivo pelo qual poderia explicar a diferença da resistência das cultivares observadas no presente trabalho. Em estudos recentes realizados com isolados de Colletotrichum provenientes do Brasil e Argentina foi relatado distintas reações de cultivares de soja ao patógeno demonstram o amplo potencial de fontes de resistência genética a C. truncatum (DIAS et al., 2019). Essa fonte parcial de resistencia também foi observada por Costa et al. (2009) ao analisar o patossistema soja $\mathrm{x}$ C. truncatum. Das 48 cultivares de soja, 17 se mostraram resistentes, 28 cultivares apresentaram reação intermediária e 3 cultivares apresentaram reação suscetível, sob condições ambientais favoráveis ao desenvolvimento do patógeno.

Ao avaliar a reação de 6 cultivares de soja inoculadas com 4 diferentes isolados de $C$. truncatum foi relatado diferença apenas entre as cultivares em função de cada 
isolado inoculado. Não houve efeito significativo quando se levou em consideração os diferentes isolados inoculados em cada cultivar (COSTA et al., 2006) o que diferencia do presente trabalho, mesmo utilizando a mesma escala diagramática para avaliar a severidade. Esses resultados podem ser justificados pelas diferenças no período de inoculação, pois plantas jovens são mais suscetíveis a infecção de C. truncatum (YANG; HATMAN, 2015). No nosso trabalho a inoculação foi realizada na semente. As mesmas ficaram em contato com o patógeno durante 12 horas.

Galli et al. (2007) observaram a influência do tempo em que as sementes de soja ficaram em contato com isolados de C. truncatum antes da semeadura. Até 16 horas foi possível diferenciar as cultivares que apresentaram maior ou menor resistência ao patógeno. No presente estudo sementes inoculadas com Colletotrichum, com formato de conídios distintos causam sintoma de tombamento pré e pós emergência, bem como lesões necróticas no pecíolo de plantas nos estádios iniciais de desenvolvimento, em todas as cultivares. Em estudo prévio, C. truncatum reduz $46 \%$ a germinação de sementes de soja e $76 \%$ a sobrevivência de plântulas (BEGUM et al., 2008).

\section{CONCLUSÕES}

Os isolados de Colletotrichum possuem ampla variabilidade na sensibilidade a diferentes ingredientes ativos e na agressividade a cultivares, o que explica a dificuldade de se controlar a antracnose na cultura da soja, no estado de Mato Grosso.

Piraclostrobina e piraclostrobina + epoxiconazol reduziram o crescimento micelial em maior número de isolados. Entretanto, não foi observado correlação entre a eficiência dos ingredientes ativos e distribuição geográfica dos isolados. Nem ao menos ao formato dos conídios.

Diante dos resultados o manejo integrado da doença com a utilização de cultivares menos sensíveis ao Colletotrichum, bem como a alternancia de ingredientes ativos são práticas essenciais para garantir o baixo índice da antracnose no estado de Mato Grosso.

\section{AGRADECIMENTOS}

Os autores agradecem a Fundação de Amparo a Pesquisa do Estado do Mato Grosso (FAPEMAT) e ao Conselho Nacional de Desenvolvimento Científico e Tecnológico (CNPq) pelo apoio financeiro.

\section{REFERÊNCIAS}

BARBIERI, M. C. G.; CIAMPI-GUILLARDI, M.; MORAES, S. R. G.; BONALDO, S. M.; ROGERIO, F.; LINHARES, R. R.; MASSOLA JUNIOR, N. S. First report of Colletotrichum cliviae causing anthracnose on soybean in Brazil. Plant Disease, Saint Paul, v. 101, n. 9, p. 1677, 2017. DOI: https://doi.org/10.1094/PDIS-0716-0963-PDN

BEGUM, M. M.; SARIAH, M.; PUTEH, A. B.; ZAINALABIDIN, M. A. Pathogenicity of Colletotrichum truncatum and its influence on soybean seed quality. International Journal of Agriculture and Biology, Punjab, v. 10, n .4, p. 393-398, 2008.
CAMPBELL, C. L.; MADDEN, L. V. Introduction to plant disease epidemiology. New York: J. Wiley \& Sons, 1990. 532p.

CHEN, L. S.; CHU, C.; LIU, C. D.; CHEN, R. S.; TSAY, J. G. PCR-based Detection and differentiation of anthracnose pathogens, Colletotrichum gloeosporioides and $C$. truncatum, from vegetable soybean in Taiwan. Journal of Phytopathology, Berlin, v. 154, p. 654-662, 2006. DOI: https://doi.org/10.1111/j.1439-0434.2006.01163.x

CONAB_Companhia Nacional de Abastecimento. Acompanhamento da safra brasileira de grãos, v. 7, n. 6, p. 31, 2020. Disponível em: https://www.conab.gov.br/info-agro/safras/graos. Acesso em: 20 mar 2020.

COSTA, I. F. D.; BALARDIN, R. S.; MEDEIROS, L. A.; BAYER, T. M. Resistencia de seis cultivares de soja ao Colletotrichum truncatum (Schwein) em dois estádios fenológicos. Ciência Rural, Santa Maria, v. 36, n. 6, p. 1684-1688, 2006.

COSTA, I. F. D.; BALARDIN, R. S.; MEDEIROS, L. A. M.; LENZ, G.; GULART, C. A.; ZEMOLIN, C. R.; SILVA, T. M. B. Reação de germoplasma comercial de soja a Colletotrichum truncatum. Tropical Plant Pathology, Brasília, v. 34, p. 47-59, 2009.

DIAS, M. D.; DIAS-NETO, J. J.; SANTOS, M. D. M.; FORMENTO, A. N.; BIZERRA, L. V. A. S.; FONSECA, M. E. N.; BOITEUX, L. S.; CAFE-FILHO, C. A. Current status of soybean anthracnose associated with Colletotrichum truncatum in Brazil and Argentina. Plants, Basel, v. 8, n. 459, 2019. DOI: https://doi.org/10.3390/plants8110459

DIAS, M. D.; FONSECA, M. E. N.; DIAS-NETO, J. J.; SANTOS, M. D. M.; PANDOLFO, G. M.; BOITEUX, L. S.; CAFE-FILHO, A. C. Biology, pathogenicity, and haplotype analyses of Colletotrichum cliviae: a novel soybean anthracnose agent in warm tropical areas. Tropical Plant Pathology, Brasília, v. 43, p. 439-451, 2018. DOI: http://dx.doi.org/10.1007/s40858-018-0249-6

DIAS, M. D.; PINHEIRO, V. F.; CAFE-FILHO, A. C. Impact of anthracnose on the yield of soybean subjected to chemical control in the north region of Brazil. Summa Phytopathologica, Botucatu, v. 42, n. 1, p. 18-23, 2016. DOI: https://doi.org/10.1590/0100-5405/2114

EMBRAPA_Empresa Brasileira de Pesquisa Agropecuária. Centro Nacional de Pesquisa de Soja. Tecnologias de produção de soja - Região Central do Brasil 2014. Londrina: Embrapa Soja, 2013. 265p.

FERREIRA, D. F. Sisvar: a computer statistical analysis system. Ciência e Agrotecnologia, Lavras, v. 35, n. 6, p. 1039-1042, 2011.

FISCHER, I. H.; SILVA, B. L.; SOARES, A. R.; ARRUDA, M. C.; PARISI, M. C. M.; AMORIM, L. Efeito de fungicidas e produtos alternativos no controle da antracnose e da pinta preta da goiaba. Semina. Ciências Agrárias, Londrina, v. 33, suplemento 1, p. 2753-2766, 2012. DOI: http://dx.doi.org/10.5433/16790359.2012v33n6Supl1p2753

GALLI, J. A.; PANIZZI, R de C.; VIEIRA, R. D. Resistência de variedades de soja a morte de plântulas causada por Colletotrichum truncatum. Arquivos do Instituto Biologico, São Paulo, v. 74, n. 2, p. 163-165, 2007.

HARTMAN, G. L.; RUPE, J. C.; SIKORA, E. J.; DOMIER, L. L.; DAVIS, J. A.; STEFFEY, K. L. Compedium of 
soybean diseases and pets, 5 th ed. St. Paul, Minnesota: APS Press, 2015. 201p.

LOPES, L. N. S.; SILVA, A. S.; PEREIRA, C. C. O.; MENEZES, I. P. P.; MALAFAIA, G.; LIMA, M. L. P. Sensibilidade de isolados de Colletotrichum gloeosporioides a fungicidas. Multi-Science Journal, Urutaí, v. 1, n. 1, p. 106-114, 2015.

MAHMODI, J. B.; KADIR, M. Y.; WONG, M. Y.; NASEHI, A.; PUTEH, A.; SOLEIMANI, N. First Report of Anthracnose Caused by Colletotrichum gloeosporioides on Soybean (Glycine max) in Malaysia. Plant Disease, Saint Paul, v. 97, n. 6, 2013. DOI: https://doi.org/10.1094/PDIS-10-12-0944-PDN

MENTEN, J. O. M.; MACHADO, C. C.; MINUSSI, E.; CASTRO, C.; KIMATI, H. Efeito de alguns fungicidas no crescimento micelial de Macrophomina phaseolina (Tass.) Goid. in vitro. Fitopatologia Brasileira, Brasília, v. 1, n. 2, p.57-66, 1976.

OLIVEIRA, J. A. Efeito do tratamento fungicida em sementes no controle de tombamento de plântulas de pepino (Cucumis sativas L.) e pimentão (Capsicum annanum L.). 1991. 111p. Dissertação (mestrado em fitossanidade), Lavras, 1991.

RAMOS, A. M.; FRANCO, T. L.; CINTO, I.; CARMONA, M.; GALLY, M. Molecular characterization of Colletotrichum species causing soybean anthracnose in Argentina. Mycotaxon, v. 123, p. 457-465, 2013. DOI: https://doi.org/10.5248/123.457

SINCLAIR, J. B. Latent infection of soybean plants and seeds by fungi. Plant Disease, v.75, n.3, p.220-224, 1991.

SOJA BRASIL. Antracnose é doença de difícil controle e danos são irreversíveis. 2014. Disponível em: http://www.projetosojabrasil.com.br/antracnose-edoenca-de-dificil-controle-e-danos-sao-irreversiveis/. Acesso em: 12 out 2015.

SOUZA, R. T. Reação de cultivares e controle da antracnose em soja. 2009. 119p. Tese (Doutorado em Agronomia) Universidade de Passo Fundo, Passo Fundo. 2009.

SUTTON, B. C. The Coelomycetes. Commonwealth Mycological Institute, Kew. 1980. 696p.

TORRES-CALZADA， C.; TAPIA-TUSSELL， R.; MARTIN-MEX, R.; NEXTICAPAN-GARCEZ, A.; PEREZ-BRITO, D. Sensibility of Colletotrichum truncatum to four fungicides and characterization of thiabendazoleresistant isolates. Plant Disease, Saint Paul, v. 99, n. 11, p. 1590-1595, 2015. DOI: https://doi.org/10.1094/PDIS-11-14-1183-RE

UNITED STATES DEPARTMENT OF AGRICULTURE (USDA), Foreign Agricultural Service Circular Series 2020 World Agricultural Production. Disponível em: https://apps.fas.usda.gov/psdonline/circulars/producti on.pdf. Acesso em: 20 fev. 2020.

YANG, H-C.; HAUDENSHIELD, J. S.; HARTMAN, G. L. Colletotrichum incanum sp. nov., a curved-conidial species causing soybean anthracnose in USA. Mycologia, New York, v. 106, p. 32-42, 2014. DOI: https://doi.org/10.3852/13-013

YANG, H-C.; HAUDENSHIELD, J. S.; HARTMAN, G. L. First Report of Colletotrichum chlorophyti causing soybean anthracnose. Plant Disease, Saint Paul, v. 96. n. 11. p. 1699, 2009. DOI: https://doi.org/10.1094/PDIS-06-120531-PDN
YANG, H-C; HARTMAN, G. L. Methods and evaluation of soybean genotypes for resistance to Colletotrichum truncatum. Plant Disease, Saint Paul, v. 99, n. 1, p. 143148, 2015. DOI: https://doi.org/10.1094/PDIS-03-140228-RE 